\title{
SH3 and PX Domain-Containing Protein
} $2 \mathrm{~A}$

National Cancer Institute

\section{Source}

National Cancer Institute. SH3 and PX Domain-Containing Protein 2A. NCI Thesaurus.

Code $C 99613$.

SH3 and PX domain-containing protein 2A (1133 aa, 125 kDa) is encoded by the human SH3PXD2A gene. This protein is involved in the formation of invadopodia. 